\title{
Primary Lymphoepithelioma-Like Carcinoma of the Lung
}

\author{
Elif TANRIVERDi,, ${ }^{1}$ Mehmet Akif ÖZGÜL, ${ }^{1}$ Özgür İşGÖRÜCÜ, ${ }^{2}$ Songül BÜYÜKKALE, ${ }^{2}$ Adnan SAYAR, ${ }^{2}$ \\ Güler ÖZGÜL, ${ }^{3}$ Demet TURAN, ${ }^{1}$ Halide Nur ÜRER, ${ }^{4}$ Erdoğan ÇETINKAYA ${ }^{1}$
}

'Department of Chest Diseases, Yedikule Chest Diseases and Thoracic Surgery Training and Research Hospital, İstanbul-Turkey

${ }^{2}$ Department of Chest Surgery, Yedikule Chest Diseases and Thoracic Surgery Training and Research Hospital, İstanbul-Turkey

${ }^{3}$ Department of Chest Diseases, Bağcılar Training and Research Hospital, İstanbul-Turkey

${ }^{4}$ Department of Medical Pathology, Yedikule Chest Diseases and Thoracic Surgery Training and Research Hospital, İstanbul-Turkey

\section{Introduction}

Primary lymphoepithelioma-like carcinoma of the lung (LELC) was reported by Begin et al. for the first time in 1987. It is a rare tumor with a prevalance ranging between $0.87 \%$ and $3.6 \%$ of the other malignancies of the lung and has been classified as a subgroup of large cell carcinoma.[1,2] LELC is usually observed in the nasopharyngeal region. It has also been described in organs originating from the foregut including oral cavity, salivary glands, lungs, stomach and thymus. [3] It has better prognosis compared to other malignant lung tumors. [4] Ebstain-Barr virus infection is thought to have a key role in tumor genesis. EBER (EBV early RNA) directed to Ebstein Barr virus RNA is typical for LELC. [5] Treatment consists of surgical resection. There is no sufficient data supporting the role of adjuvant treatment.

\section{Case Report}

A 45-year-old woman presented with left hilar enlargement and nodule in the left lower zone on posteroanterior lung graphy (Figure 1). Her personal and familial history revealed no previous disease. Physical examination and preliminary laboratory findings were normal.

Thorax computarized tomography revealed a left hilar lesion, 30x28 mm in diameter, that could be either a mass lesion or a lymph node, and a nodular lesion with irregular borders with a size of $18 \times 16 \mathrm{~mm}$ in the superior segment of the left lower lobe (Figure 2).

PET CT revealed intensively increased FDG uptake in the left hilar mass (SUV MAX 15.3) and FDG uptake in the nodule localized in the left lower lobe (SUV MAX 8.8). Transbronchial needle aspiration biopsy was performed to the hilar lesion under guidance of 


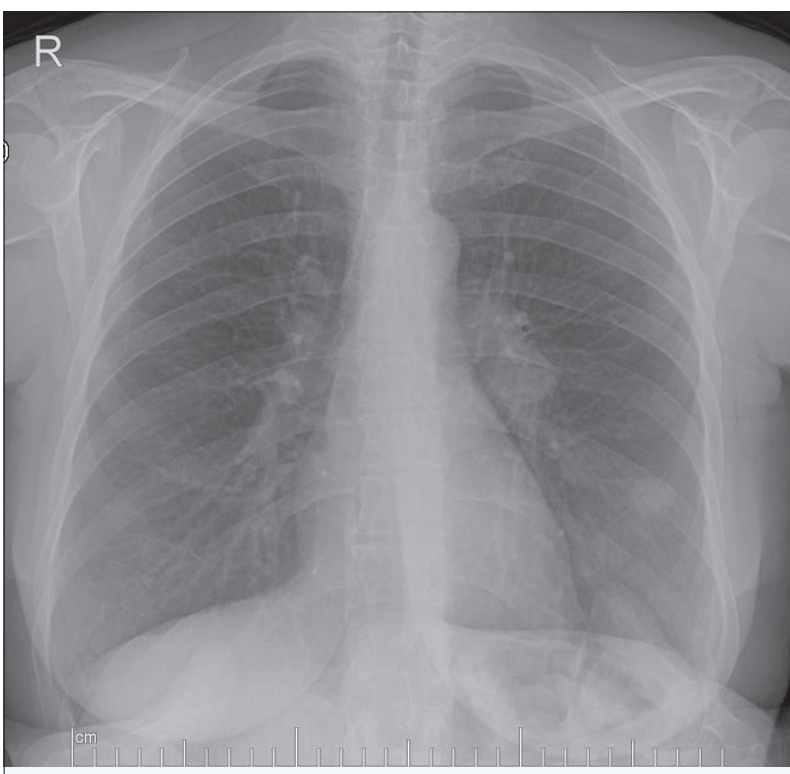

Fig. 1. Left hilar enlargement and nodule in the left lower zone on PA lung graphy.

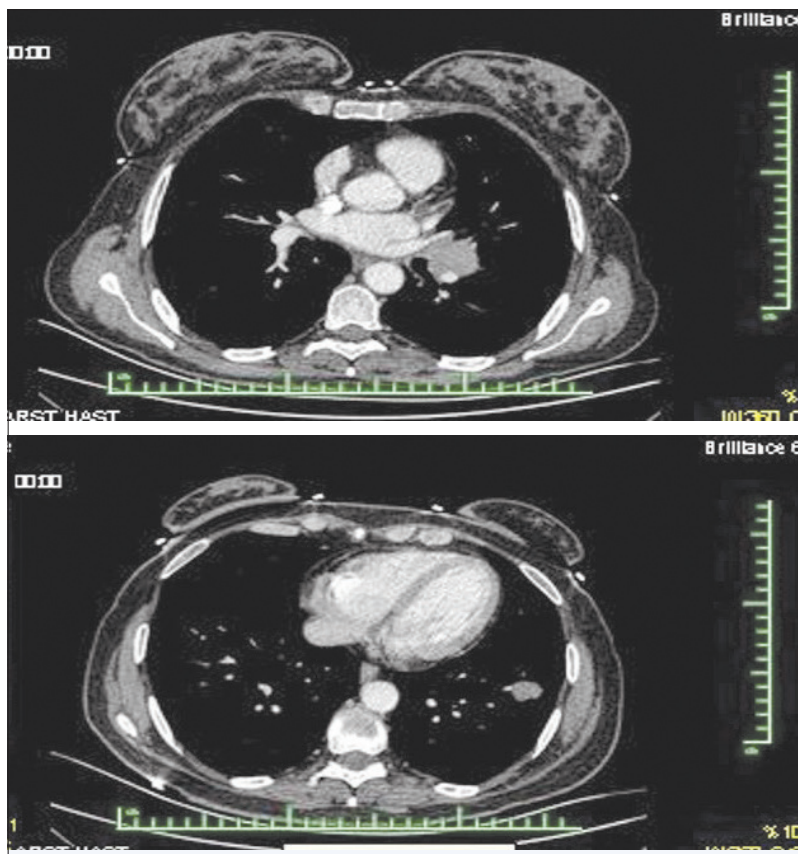

Fig. 2. Appearance of hilar lynmph node and nodule on thoracal CT.

convex probe endobronchial ultrasonography (CPEBUS) (Figure 3).

Pathological examination of the biopsy material was reported as non-small cell lung carcinoma and considered grade $2 \mathrm{~A}$. Since there was no distant metastasis on PET-Ct and Cranial MRI, left-sided pneumo-

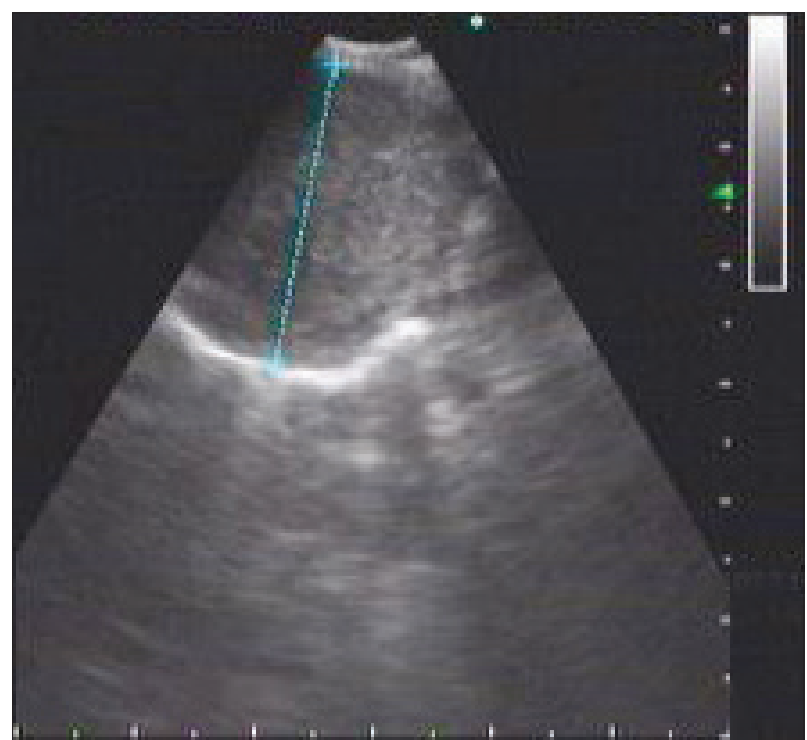

Fig. 3. EBUS-TBIA from the area number 11 on the left side.

nectomy was performed. Polygonal epitheloid tumor cells with large nuclei were observed inside an intense population of lymphoplasmacytic cells on pathological examination (Figure 4) and EBER was found positive (Figure 4). The findings were compatible with LELC.

Nasopharyngeal examination of our patient was normal. Serologic tests were performed and EBV VCA IgM was negative and EBV VCA IgG and EBNA IgG were positive. Six courses of carboplatin and paclitaxel were administered following surgery. The patient is still in remission.

\section{Discussion}

Primary LELC (lymphoepithelioma-like carcinoma of the lung) occurs considerably rare and it is differentiated from large cell indifferentiated carcinoma of the lung as a histological entity.[2] It occurs with an equal frequency in males and females. It affects the young population with no smoking history with a higher rate. [6] The relationship of the tumor with EBV shows a significant geographic and ethnic variability. While its relationship with EBV is substantially strong in Asian people, this relationship has not been observed in Caucasians.[7] Our patient who had no previous history of smoking was serologically evaluated in terms of EBV infection and EBV VCA IgM was negative and EBV VCA IgG and EBNA IgG were positive. It is difficult to differentiate primary LELC and metastasis of nasopharyngeal cancer histologically. Therefore, patients should be clinically examined and investigated further 


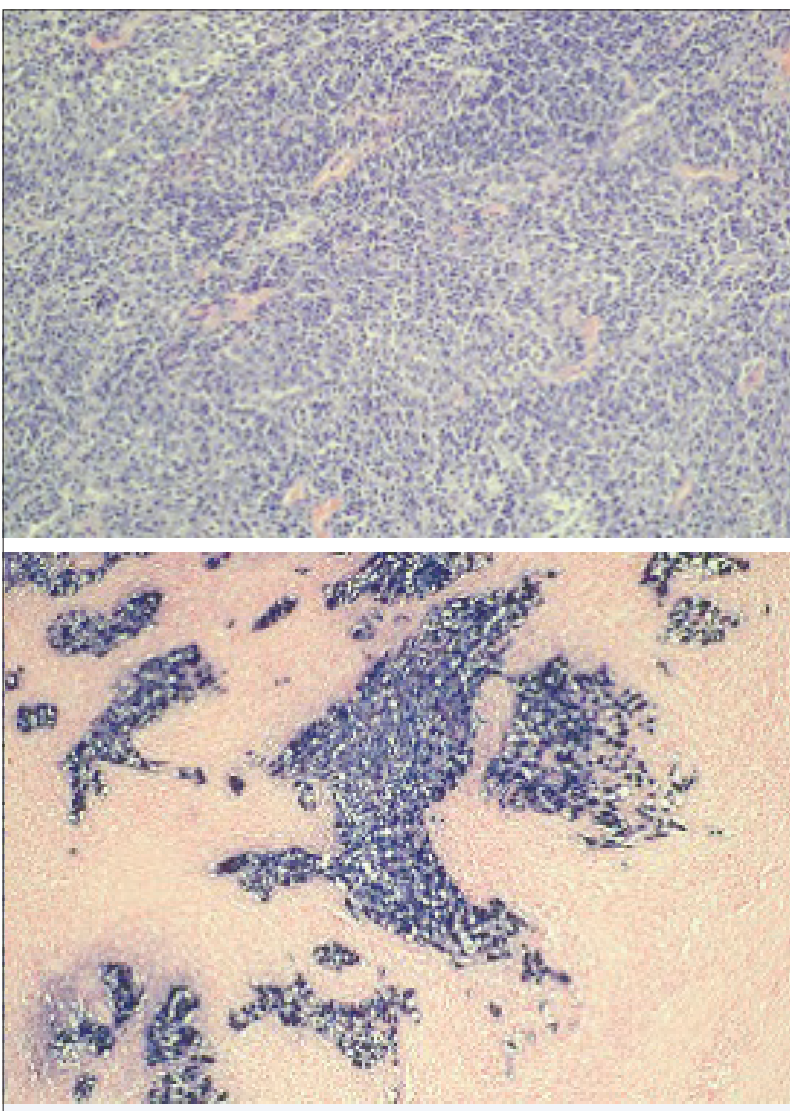

Fig. 4. Polygonal epitheloid tumor cells with large nuclei inside an intense population of lymphoplasmacytic cells H\&E x200; EBER positivity.

in terms of nasopharyngeal cancer.[7] Physical examination and PET/CT of the nasopharnyx were normal. It was reported that primary LELC frequently presented as a peripheral nodule with irregular borders with a size of $3.5 \mathrm{~cm}$ or smaller and did not lead to lymphadenopathy in the clinicopathological studies of Han et al., Hoxworth et al. and Chan et al. [4,8,9] In the study of Ooi et al., it was observed that it presented as a large thoracic mass with regular borders in the $1 / 3$ central part of the lungs and lymphadenopathy accompanied. [10] Interestingly, the nodular lesion with irregular borders was localized more peripherally in our patient, but lymphadenopathy was also present.

The histopathological differential diagnosis of the tumor includes poorly differentiated carcinoma, malignant melanoma and malignant lymphoma. Presence of mixed type inflammatory cell infiltration associated with absence of monoclonality in the lymphoid cells on histopathological examination is important in differentiating LELC fom other lymphoid malignancies. It is considerably difficult to make a diagnosis of
LELC, because it is observed very rarely in small biopsy samples which represent a very small part of the tumor considering lung malignancies which demonstrate a heterogeneous structure.[2] In some case reports, it has been reported that a definite diagnosis of LELC is made by way of large excision or post-operative tissue-based sampling in the presence of a lesion which is interpreted as undifferentiated non-small-cell carcinoma by needle biopsy.[11,12] Among various diagnostic methods, EBER positivity is the most specific and considerably highly sensitive method for differentiation of LELC from other lung malignancies.[11] Our patient was primarily diagnosed with non-smallcell lung carcinoma by EBUS-TBNA, surgery was performed and the histopathological diagnosis was found to be compatible with LELC. The diagnosis was supported with EBER positivity. Treatment strategies are still controversial since it is observed rarely. LELC is sensitive to chemotherapy and radiotherapy. Generally, radical surgical treatment is performed in early stage disease and surgery and chemoradiotherapy combination is performed in local advanced or metastatic disease. Platinum-based chemotherapy regimens may be administered. EGFR and ALK expression in LELC is considerably rare and target-specific threatment regimens are not beneficial. New studies are needed for new treatment modalities.[13-16] Six courses of platinum-based chemotherapy were administered following surgery in our patient. At the present time, she is in remission and being followed up.

In conclusion, LELC is a very rare subtype of nonsmall-cell lung carcinoma. Histologically, it is difficult to differentiate primary LELC from metastatic nasopharyngeal carcinoma. All patients should be investigated for nasopharyngeal cancer, when LELC is found. Its prognosis is better compared to non-small-cell carcinoma. Surgical resection procedures should be applied, if patients are clinically operable.

\section{Disclosure Statement}

The authors declare no conflicts of interest.

\section{References}

1. Begin LR, Eskandari J, Joncas J, Panasci L. EpsteinBarr virus related lymphoepithelioma- like carcinoma of lung. Journal of Surgical Oncology 1987;36(4):2803.

2. Özkan S, Yazıcı Ü, Aydın E, Özaydın E, Karaoğlanoğlu N. Primary lymphoepithelioma like carcinoma 
of the Lung: A Case Repor. Eurasian J Pulmonol 2014;16:127-9.

3. Huang YC, Hsueh C, Ho SY, Liao CY. Lymphoepithelioma-like carcinoma of the lung: An unusual case and literature review. Case Rep Pulmonol 2013;2013:143405.

4. Han AJ, Xiong M, Gu YY, Lin SX, Xiong M. Lymphoepithelioma-like carcinoma of the lung with a better prognosis. A clinicopathologic study of 32 cases. Am J Clin Pathol 2001;115(6):841-50.

5. Hayashi T, Haba R, Tanizawa J, Katsuki N, Kadota K, Miyai Y, et al. Cytopathologic features and differential diagnostic considerations of primary lymphoepithelioma-like carcinoma of the lung. Diagn Cytopathol 2012;40(9):820-5.

6. Liang Y, Wang L, Zhu Y, Lin Y, Liu H, Rao H, et al. Primary pulmonary lymphoepithelioma-like carcinoma: fifty-two patients with long-term follow-up. Cancer 2012;118:4748-58.

7. Bildirici K, Ak G, Peker B, Metintas M, Alatas F, Erginel S, Ucgun İ. Primary lymphoepithelioma-like carcinoma of the lung. Tuberk Toraks 2005;53(1):69-73.

8. Hoxworth JM, Hanks DK, Araoz PA, Elicker BM, Reddy GP, Webb WR, et al. Lymphoepithelioma-like carcinoma of the lung: Radiologic features of an uncommon primary pulmonary neoplasm. AJR Am J Roentgenol 2006;186(5):1294-9.

9. Chan JK, Hui PK, Tsang WY, Law CK, Ma CC, Yip TT, et al. Lymphoepithelioma-like carcinoma of the lung. A clinicopathologic study of 11 cases. Cancer
1995;76(3):413-22.

10. Ooi GC, Ho JC, Khong PL, Wong MP, Lam WK, Tsang KW. Computed tomography characteristics of advanced primary pulmonary lymphoepithelioma-like carcinoma. Eur Radiol 2003;13(3):522-6.

11. Jeong JS, Kim SR, Park SY, Chung MJ, Lee YC. A Case of Primary pulmonary lymphoepithelioma-like carcinoma misdiagnosed as adenocarcinoma. Tuberc Respir Dis 2013;75:170-3.

12. Yener NA, Balikçi A, Çubuk R, Mıdı A, Örkı A, Eren Topkaya A. Primary lymphoepithelioma-like carcinoma of the lung: report of a rare case and review of the literature. Turk Patoloji Derg 2012;28(3):286-9.

13. Liang Y, Shen C, Che G, Luo F. Primary Pulmonary Lymphoepithelioma-like carcinoma initially diagnosed as squamous metaplasia: A case report and literature review. Oncol Lett 2015;9(4):1767-71.

14. Jiang L, Wang L, Li P, Zhang X, Chen J, Qui H, et al. Positive expression of programmed death ligand- 1 correlates with superior outcomes and might be a therapeutic target in primary pulmonary lymphoepithelioma-like carcinoma. Onco Targets Ther 2015;8:1451-7.

15. Huang C, Feng A, Fang Y, Ku W, Yu C, Liu C, et al. Multimodality treatment and long-term follow-up of primary pulmonary lymphoepithelioma-like carcinoma. Clin Lung Cancer 2012;13(5):359-36.

16. Jiang WY, Wang R, Pan XF, Shen YZ, Chen TX, Yang $\mathrm{YH}$, Shao JC, et al. Clinicopathological features and prognosis of primary pulmonary lymphoepitheliomalike carcinoma. J Thorac Dis 2016;8(9):2610-6. 